\title{
Cervical proprioception and its relationship with neck pain intensity in subjects with cervical spondylosis
}

\author{
Ravi Shankar Reddy ${ }^{1 *}$ D, Jaya Shanker Tedla', Snehil Dixit ${ }^{1}$ and Mohammed Abohashrh ${ }^{2}$
}

\begin{abstract}
Background: Cervical proprioception is critical in the maintenance of posture and movements, so its assessment in different cervical conditions has gained importance in recent clinical practice. Studies reporting this assessment in subjects with cervical spondylosis (CS) have not previously been investigated. The goals of the study are (1) comparison of joint position error (JPE) in subjects with CS to healthy control group. (2) Correlation of neck pain intensity to cervical proprioception in patients with CS.
\end{abstract}

Methods: In a Cross-sectional study, 132 subjects with CS and 132 healthy age-matched control subjects were evaluated for cervical JPE with the cervical range of motion device. The subjects were blindfolded and repositioned their heads to a target position, which was determined by the examiner previously and their repositioning accuracy (absolute error in degrees) was measured in the frontal (flexion and extension) and transverse planes (left rotation and right rotation). The CS subjects resting neck pain intensity was assessed using visual analog scale (VAS).

Results: CS subjects showed statistically significantly larger JPEs compared to healthy control subjects in all the directions tested (flexion - 95\% Cl=2.38-3.55, $p<0.001$, extension - 95\% Cl =3.26-4.33, $p<0.001$, left rotation $-95 \% \mathrm{Cl}=2.64-3.83$, $p<0.001$, right rotation $-95 \% \mathrm{Cl}=3.77-4.76, p<0.001$ ). The mean JPE errors in the CS group ranged from $6.27^{\circ}$ to $8.28^{\circ}$ and in the control group ranged from $2.36^{\circ}$ to $4.48^{\circ}$. Pearson's correlation coefficient showed a significant and positive relationship between neck pain intensity and cervical proprioception ( $p \leq 0.001$ ).

Conclusions: Proprioception is impaired in subjects with CS when compared to healthy control group. Higher pain intensity was associated with greater cervical JPE in patients with CS.

Keywords: Neck pain, Cervical spondylosis, Proprioception, Pain intensity

\section{Background}

Cervical spondylosis (CS) is an age-related chronic degenerative condition of the cervical spine with a prevalence rate of 3.3 patients per 1000 people in the general population $[1,2]$. The usual occurrence of CS is at $\mathrm{C} 5-\mathrm{C} 6$ and $\mathrm{C} 6-\mathrm{C} 7$ levels, although higher levels may also be involved [3]. Even though age-related degeneration is the primary cause of degeneration, in younger patients injuries to the cervical disc can affect this degenerative process. Subjects with CS usually present with complaints of pain, tingling, numbness and weakness in

\footnotetext{
* Correspondence: rshankar@kku.edu.sa

'Department of Medical Rehabilitation (Physical Therapy), College of Applied Medical Sciences, King Khalid University, Abha 61421, Saudi Arabia Full list of author information is available at the end of the article
}

the upper extremity, which will lead to significant disability and functional limitations [3].

Proprioception is a sense of bodily movement position, which includes position sense (joint position sense) and movement sense (kinesthesia) [4]. The ascending proprioceptive information reaches the central nervous system via the afferent pathway contributing to movement and postural neuromuscular control [4]. The cervical muscles have abundant muscle spindle density that reflects a rich proprioceptive system, which contributes to enhanced sensorimotor function and thereby play an important role in maintaining static and dynamic postures with effective motor control [5].

Studies have shown that cervical position sense is vital in maintaining joint stability under static and dynamic 
conditions and the development of clinical pain is predisposed by impaired proprioception [6]. Cervical proprioception is quantified by joint position error (JPE) measured in degrees. In CS, if the non-specific nature of problems is paired with impaired cervical proprioception, it is more likely that position sensibility is primarily affected by impairment in cervical muscles, joints, or capsules and, secondarily, by alteration in afferent proprioceptive tuning and integration $[7,8]$. In CS, there may be impaired mechanoreceptor's feedback, which might contribute to cervical muscle atrophy and joint degenerative changes resulting in unpredictable "giving away." $[8,9]$

An impaired position sense disturbs both neuronal and muscular control of the normal cervical joint function, which may result in the untimely production of unbalanced muscle force and place the joint at risk of trauma $[8,9]$.

Cervical pain can originate from a local spot or can spread to distant areas and develop into chronic syndrome in subjects with CS $[8,9]$. Acute pain transforming into chronic pain is a complex process and not fully understood by researchers, and thereby the intensity of pain is a focus of research on subjects with neck pain [9-11]. Lee et al. conducted a study to show if there is any association between temporal aspects of pain (Pain frequency, duration, intensity) and cervical position sense in subjects with subclinical neck pain [6]. The neck pain intensity did not show consistent effect with cervical proprioceptive ability. Lee did not see consistent association may be because he sub grouped subjects as mild, moderate and severe pain intensity groups and compared the proprioception errors rather than seeing association between each subject pain intensity to his proprioceptive ability. To date, there are no studies that showed a consistent relationship between neck pain intensity and cervical proprioception, possibly because neck pain intensity is not easily quantified due to its subjective nature, particularly if neck pain is subclinical or occasional. Another approach is to evaluate the temporal aspect of pain intensity and its influence on neck proprioception in CS subjects. Therefore, the purpose of the study is to see the comparison of joint position error in subjects with CS to healthy control group and to see a relationship between neck pain intensity and cervical proprioception in patients with CS. The hypothesis of the study is that 1) cervical JPE will be greater in CS group compared to healthy control group. 2) Higher cervical pain intensity will be associated with greater cervical JPE in subjects with CS.

\section{Methods}

Our study is a cross-sectional analysis and the subjects in this study's sample were patients aged 30 to 60 years experiencing neck pain due to CS and referred from the orthopedic or neuro-medicine clinic to physical therapy. CS is defined as "neck pain subjects with the radiological findings confirming cervical degeneration (degenerative changes in the intervertebral discs, osteophytosis of the vertebral bodies, hypertrophy of the facets and laminal arches, and ligamentous and segmental instability) and cervical range is limited when compared with agematched healthy subjects." Subjects were included if the neck pain was the main presenting complaint, and if neck movements reproduced neck pain. Subjects with a history of neurologic disease, whiplash injury, cervical myelopathy, any inflammatory arthritis, tumors, infection involving the cervical spine, and vertebrobasilar artery insufficiency were excluded. For the age-matched healthy control subjects to be considered for inclusion, the subjects must have age-matched normal cervical spine ROM in all the planes, with no history of cervical spine injury, dizziness, or vertigo, or any other musculoskeletal complaints. All the subjects included in the study signed a consent form and the King Khalid University Ethics Committee approved the study (REC \# 2016-01-06).

\section{Cervical JPE testing}

The testing procedures implemented in this study are those adopted by Lee et al. [6]. The subjects sat upright in the chair with back straight, head facing straight ahead, and feet touching the ground, and this position was selected as the neutral head position. The study procedure was explained to all the subjects and standard instructions were given during their testing phase. A travel eye mask was used to blindfold the subject and a Velcro strap was used to fix and limit trunk and shoulder movement during the JPE testing procedure (Figs. 1 and 2).

The examiner secured the cervical range of motion (CROM) unit on the subject's head with the Velcro strap and the magnetic yoke of the CROM device was arranged on the subject's shoulder with arrow mark placed to the north. With the above position maintained, the examiner calibrated the CROM device to a neutral position. CROM is a valid device to measure cervical ROM and intratester reliability ranged from 0.62 to 0.91 and inter-tester reliability ranged from 0.74 to 0.87 [12]. To evaluate the JPE, the examiner held the subject's head and moved slowly to the target head position, which is $50 \%$ of the maximum CROM (which was previously recorded by the examiner) [13] and held there for a period of $3 \mathrm{~s}$. The subjects then memorized that target position and then the examiner slowly brought the subject's head back to the neutral position. The subjects then were advised to reach the target position actively by moving the head and when subject reached the target position the reposition accuracy error was determined in 


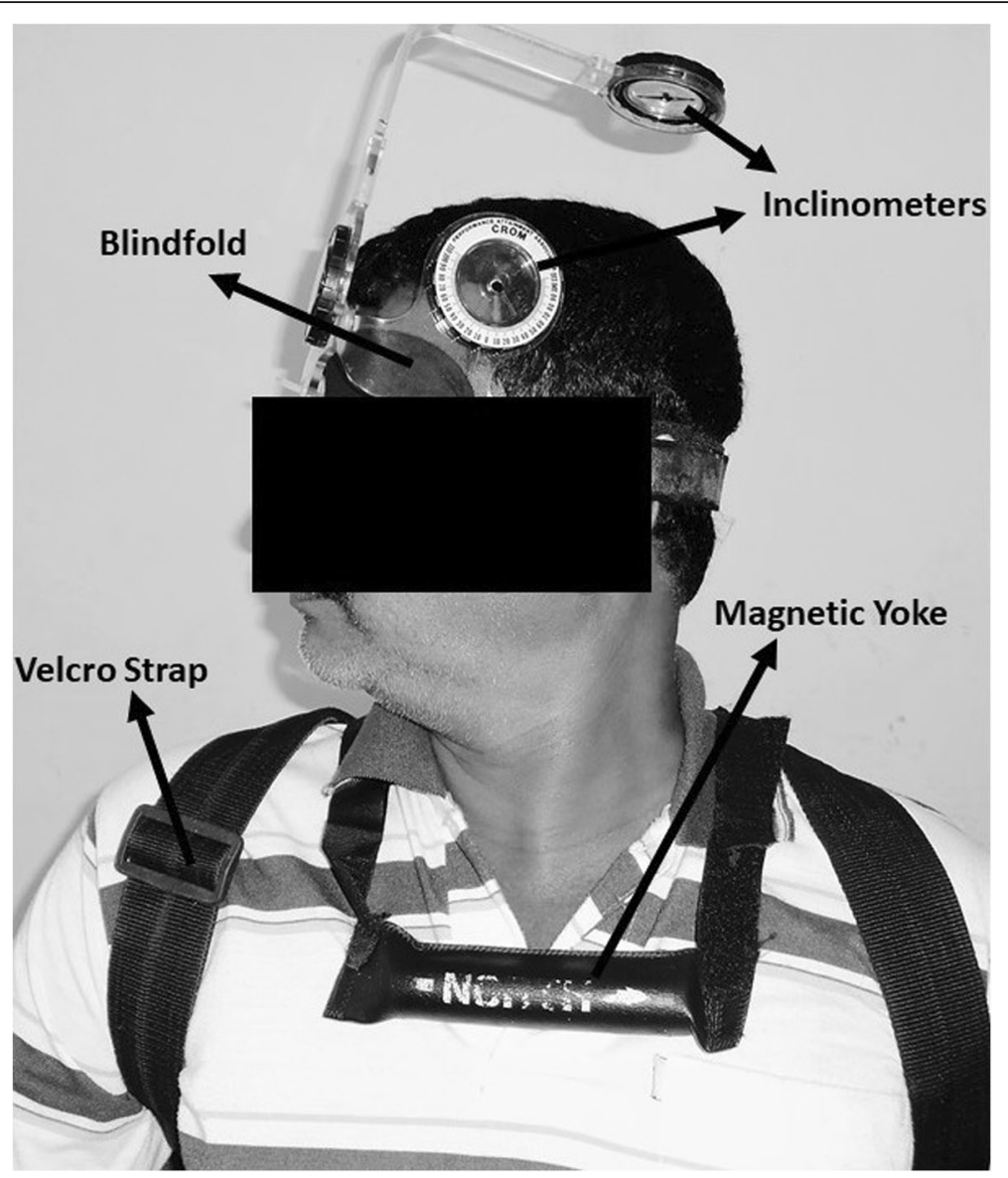

Fig. 1 Procedure to evaluate cervical joint position error

degrees. The examiner evaluated JPE tests in sagittal (flexion, extension) and transverse plane (right and left rotation) directions. A simple chit method was adopted to randomize this order of testing. Each direction of JPE testing was performed three times and the mean error of these trials was used in the analysis. A single investigator administered all tests and no feedback was provided to the subjects during the testing procedure. The JPE tests were then compared between CS and healthy control subjects.
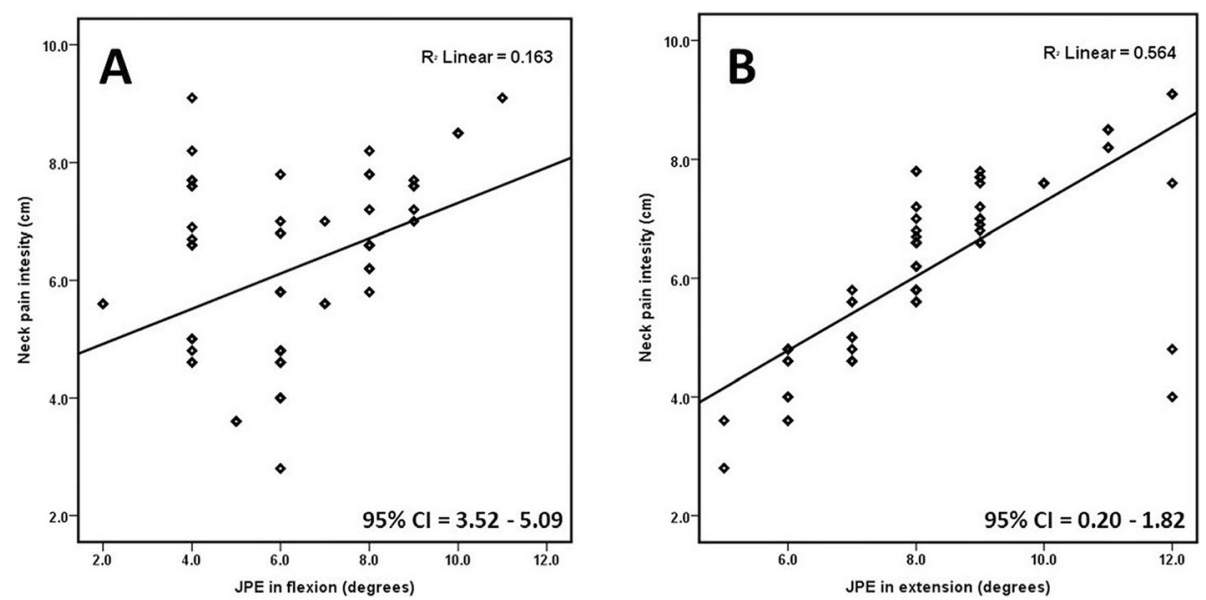

Fig. 2 Relationship between neck pain intensity and a JPE in flexion $\left({ }^{\circ}\right)$, b JPE in extension $\left(^{\circ}\right)$ 


\section{Neck pain assessment}

The CS subjects resting neck pain intensity was assessed using visual analog scale (VAS). The VAS is a psychometric response scale. When responding to a VAS item, patients make marks along the $100 \mathrm{~mm}$ line at the point they feel represents their current pain state. The VAS has been used extensively as an outcome measure. It has high test-retest reliability and validity [14].

\section{Statistical analysis}

SPSS version 20.0 (IBM-SPSS Inc., Armonk, NY) was used to perform data analysis. All statistical values with $p \leq 0.05$ were considered significant. All the values are represented as mean $\pm \mathrm{SD}$.

A Shapiro-Wilk test showed that the study data were normally distributed so an independent $t$ test was used to compare cervical JPE differences between CS and healthy control subjects. Minimal detectable change (MDC) was computed, which is a statistical estimation of the minimum quantity of change that can be identified by a measure that matches to a noticeable true change in capacity versus a false or error change. MDC was computed by the formula: (Standard Error Mean $(\mathrm{SEM}) \times 1.65 \times \sqrt{2}$ ), where $\mathrm{SEM}=$ standard deviation of the sample mean [15]. Pearson's correlation coefficient (r) was computed to investigate the linear relationship between neck pain intensity and cervical JPE. We considered Pearson's $r>0.75=$ strong, $r$ between 0.45 and $0.75=$ moderate, and $\mathrm{r}$ below $0.45=$ weak correlation [16].

\section{Results}

In this study, the sample size was 264 people (132 patients in each group). CS and healthy control groups showed no significant statistical differences for age, gender, and body mass index (BMI) $(p>0.05)$ (Table 1) at baseline. CS subjects showed significantly larger JPE than healthy control subjects in all the directions tested (flexion, extension, right and left rotation) with a $p$-value $<0.001$ (Table 2).

Comparing all the movement directions in the CS and healthy control groups, the JPEs were largest in cervical extension (CS groups $=8.28 \pm 1.80^{\circ}$; healthy group $=$ $4.48 \pm 1.26^{\circ}$ ) with SEM of $0.21^{\circ}$ and minimal detectable

Table 1 Demographic characteristics of the study population

\begin{tabular}{llll}
\hline Variables & $\begin{array}{l}\text { Cervical spondylosis } \\
\text { Group }\end{array}$ & $\begin{array}{l}\text { Control } \\
\text { Group }\end{array}$ & $p$ value \\
\hline Age (years) & $47.18 \pm 6.54$ & $45.07 \pm 8.02$ & 0.100 \\
Gender $(\mathrm{n})$ & $96: 36$ & $100: 32$ & 0.693 \\
BMl $\left(\mathrm{kg} / \mathrm{m}^{2}\right)$ & $24.30 \pm 2.99$ & $24.24 \pm 2.21$ & 0.458 \\
Neck pain intensity & $6.21 \pm 1.50$ & 0 & $<0.001$ \\
$(\mathrm{~cm})$ & & & $<0.001$ \\
NDI score (\%) & $31.81 \pm 10.66$ & 0 &
\end{tabular}

$B M I$ body mass index, NDI neck disability index change (MDC) of $0.48^{\circ}$. The smallest JPE was seen for rotation left in the CS group $\left(6.27 \pm 1.96^{\circ}\right)$ with SEM of $0.20^{\circ}, \mathrm{MDC}$ of $0.46^{\circ}$ and right rotation in the healthy control group $\left(2.36 \pm 1.03^{\circ}\right)$ with SEM of $0.22^{\circ}$, MDC of $0.51^{\circ}$ (Table 2).

Pearson's correlation coefficient $(r)$ showed a positive and significant relation between neck pain intensity and JPEs in all directions tested as summarized in Fig. 3 and Table 3. A strong positive correlation was seen between neck pain intensity and JPE in left rotation with Pearson's $r=0.78 ; \mathrm{CI}=1.76-3.33 ; p<0.001$ and moderate positive correlation was observed between neck pain intensity and JPE in flexion $(r=0.67 ; \mathrm{CI}=3.52-5.09 ; p=$ $0.001)$, extension $(r=0.59 ; \quad \mathrm{CI}=0.20-1.82 ; \quad p<0.001)$, and right rotation $(r=0.66 ; \mathrm{CI}=2.98-4.48 ; p<0.001)$.

\section{Discussion}

This study demonstrated that cervical proprioceptive errors (JPEs) are significantly larger in the CS group than in the healthy control group indicating that cervical proprioception is impaired in subjects with CS. Cervical proprioceptive errors in the CS group significantly and positively correlated with neck pain intensity. The cervical JPE increased with increased neck pain intensity showing that an increase in pain intensity will impair the proprioceptive functionality.

This study finding, which showed substantial proprioceptive impairment in terms of increased JPE in the CS group, is in accordance with findings from previously published results that involved subjects with other types of neck conditions $[6,9,17,18]$. Rix et al.'s study showed a mean JPE of $6.3^{\circ}$ in flexion, $5.2^{\circ}$ in extension, $6.9^{\circ}$ in right rotation, and $4.2^{\circ}$ in left rotation in subjects with chronic, non-traumatic cervical spine pain [18]. In Roren et al., the study demonstrated an absolute error of $3.6^{\circ}$ to $3.7^{\circ}$ for healthy subjects and $6.1^{\circ}$ to $6.3^{\circ}$ for neck disorder subjects when a subject's head reposition was measured with an ultrasound-based technique [19]. Wibault et al. conducted a study on subjects with cervical radicular symptoms caused by disc prolapse and showed a smaller mean JPE of $3.8^{\circ}$ in right rotation and $2.7^{\circ}$ in left rotation [20] compared with our study results (right rotation $=6.63^{\circ}$, left rotation $=6.27^{\circ}$ ). These may be due to the differences in methodological considerations in both studies. Caution should be exercised when comparing our study results for cervical JPE with studies previously published because of differences in study methods, evaluations, and interpretations used.

The reasons for the impaired proprioception in the CS group may be due to the following causes. In CS there may be altered proprioceptive afferent signals from the skin, joints, and muscle spindle receptors due to degenerative changes to capsuloligamentous structures and mechanoreceptors [21] as well as muscle dysfunction 
Table 2 Comparison of JPE between cervical spondylosis and control group

\begin{tabular}{|c|c|c|c|c|c|c|c|c|}
\hline \multirow[t]{2}{*}{ Variables } & \multirow{2}{*}{$\begin{array}{l}\text { Cervical Spondylosis } \\
\text { group } \\
(n=132) \\
\text { (Mean } \pm \text { SD) }\end{array}$} & \multirow[b]{2}{*}{$\begin{array}{l}\text { Healthy } \\
\text { control } \\
\text { group } \\
(n=132) \\
\text { (Mean } \pm \\
\text { SD) }\end{array}$} & \multirow{2}{*}{$\begin{array}{l}\text { Actual } \\
\text { Difference } \\
\text { between } \\
\text { CS and } \\
\text { Control } \\
\text { group }\end{array}$} & \multicolumn{2}{|l|}{$95 \% \mathrm{Cl}$} & \multirow[t]{2}{*}{ SEM } & \multirow[t]{2}{*}{ MDC } & \multirow[t]{2}{*}{$p$ value } \\
\hline & & & & Lower & Upper & & & \\
\hline JPE in flexion $\left(^{0}\right)$ & $6.33 \pm 2.02$ & $3.36 \pm 1.27$ & 2.97 & 2.38 & 3.55 & 0.19 & 0.44 & $<0.001$ \\
\hline JPE in extension $\left({ }^{0}\right)$ & $8.28 \pm 1.80$ & $4.48 \pm 1.26$ & 3.80 & 3.26 & 4.33 & 0.21 & 0.48 & $<0.001$ \\
\hline JPE in left rotation $\left({ }^{0}\right)$ & $6.27 \pm 1.96$ & $3.03 \pm 1.45$ & 3.24 & 2.64 & 3.83 & 0.20 & 0.46 & $<0.001$ \\
\hline JPE in right rotation $\left({ }^{0}\right)$ & $6.63 \pm 1.75$ & $2.36 \pm 1.03$ & 4.27 & 3.77 & 4.76 & 0.22 & 0.51 & $<0.001$ \\
\hline
\end{tabular}

$J P E$ joint position error, $\mathrm{Cl}$ confidence interval, SEM standard error of the mean, $M D C$ minimal detectable change

[22]. The decrease in cervical muscle strength has been established in neck pain syndromes like CS [23-25]. The reported decrease in cervical muscle strength compared with healthy individuals varies by about 20 to $90 \%$ [23, 25-27]. Patients with CS have been shown to exhibit greater fatigue and weakness of both deep flexor and dorsal neck extensor muscles at high force levels compared with healthy subjects at electromyography [28]. Decreased muscle strength and increased muscle fatigue can alter the firing of sensory receptors (Golgi tendon organ or muscle spindles) and thereby influence afferent inputs resulting in altered proprioception [29, 30].

To date, to our knowledge, this is the first study of its kind that has evaluated and shown a significant positive correlation between neck pain intensity and position sense in subjects with CS. Pain models that were experimentally induced showed a positive influence between pain and proprioception [31]. The substances that are chemically mediated during the pain response might alter free nerve ending discharges due to sensitization and produce abnormal pain afferents (gamma-motor neuron and muscle spindle), thus impairing kinesthetic input [32]. Contrary to our study, Lee et al.'s study did not show any association between neck pain intensity and cervical proprioceptive sense in chronic neck pain subjects; rather, they noted that a higher pain frequency was positively associated with increased JPEs [6]. Our study results cannot be compared with et al. study as the sample characteristics and cervical proprioception testing methodological considerations are different from the current study. Further studies are required to see the association between neck pain frequency, duration, and intensity and proprioception in a larger sample of CS subjects.

To measure cervical proprioception, this study implemented the active head repositioning to the target method, which was previously used by several authors in clinical settings $[13,33,34]$ and was found to be a reliable method. The number of testing trials or movement repetitions in each direction was limited to three to minimize the effect of fatigue of cervical muscles on JPE. Different authors recommended a greater number of trials in each testing direction to improve the reliability of position sense measurement [35], but increasing the
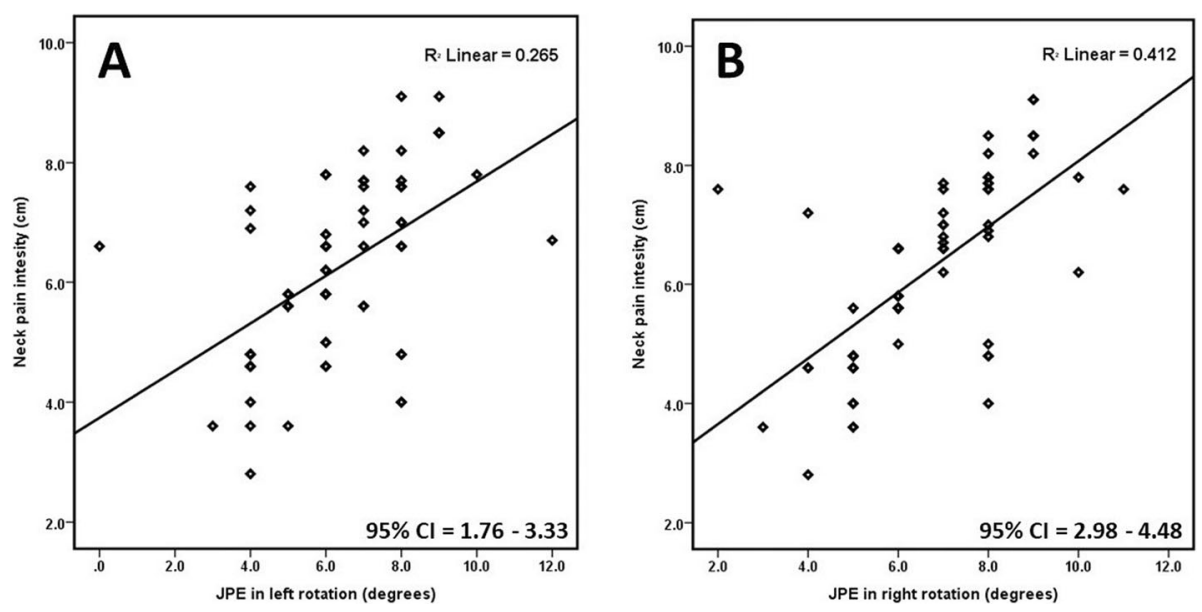

Fig. 3 Relationship between neck pain intensity and a JPE in left rotation $\left({ }^{\circ}\right)$, b JPE in right rotation $\left(^{0}\right)$ 
Table 3 Coefficient of correlation between pain intensity and joint position errors in CS subjects

\begin{tabular}{llllll}
\hline & & $\begin{array}{l}\text { JPE in } \\
\text { Flexion } \\
\left({ }^{(}\right)\end{array}$ & $\begin{array}{l}\text { JPE in } \\
\text { extension } \\
\left({ }^{(}\right)\end{array}$ & $\begin{array}{l}\text { JPE in left } \\
\text { Rotation }\left(^{0}\right)\end{array}$ & $\begin{array}{l}\text { JPE in right } \\
\text { rotation }\left(^{(}\right)\end{array}$ \\
\hline $\begin{array}{l}\text { Neck pain } \\
\text { intensity }(\mathrm{cm})\end{array}$ & $\mathrm{r}$ & 0.67 & 0.59 & 0.78 & 0.66 \\
$95 \% \mathrm{Cl}$ & Lower & 3.52 & 0.20 & 2.98 & 1.76 \\
& Upper & 5.09 & 1.82 & 4.48 & 3.33 \\
& $\mathrm{p}$ & 0.001 & $<0.001$ & $<0.001$ & $<0.001$ \\
\hline
\end{tabular}

CS cervical spondylosis, JPE joint position error, $\mathrm{Cl}$ confidence interval

number of repetitions can possibly lead to increased pain and fatigability, which may alter the test results of JPEs in subjects with CS.

\section{Limitations}

The self-assessment of neck pain intensity on a VAS by the subject may be influenced by many factors like beliefs, socio-economic status or psychological status as pain is a subjective feeling and there by influencing the study results. The present study recorded absolute errors only. Variable and constant errors were not observed or else direction and magnitude of JPEs have been recorded, which might have given more meaningful information regarding the direction of JPEs tested. All the subjects were assessed for cervical JPE only after a single practice session may be results would be different if more practice sessions were provided to the subjects prior to the actual testing.

\section{Conclusion}

CS subjects showed significantly greater cervical JPEs than healthy controls in all the movement directions tested. Hence, this study proved proprioception is impaired in subjects with CS, and a higher pain intensity was associated with greater cervical JPE.

\section{Abbreviations}

CROM device: Cervical range of motion device; CS: Cervical spondylosis; JPE: Joint position error

\section{Acknowledgements}

Not Applicable

\section{Authors' contributions}

RSR, JST, SD and MA were involved in planning, design and ethic approvals for the CS cases reported. RSR, JSR and SD were responsible for CS patient recruitment; collected the data; RSR performed statistical analysis; JST, SD and MA analyzed the data and RSR, JST, SD and MA interpreted the results. RSR, JST, SD and MA developed the manuscript and agreed to its final submission. All authors promise for the integrity of the content and study. All authors read and accepted the final manuscript.

\section{Funding}

Internal Funding (R.G.P.1/133/40) was received from the King Khalid University. Abha. Saudi Arabia. The funding unit of the study had no role in the study methodological design, data collection or analysis or interpretation. The data is under the responsibility of corresponding author and has full rights to choose the journal and submit for publication.

\section{Availability of data and materials}

All data are available at the medical rehabilitation department (College of Applied Medical Sciences) on application to the primary author Ravi Shankar Reddy (rshankar@kku.edu.sa).

\section{Ethics approval and consent to participate}

University ethics committee approved the study (Reference no: MUEC 16/ 2008). All the subjects signed a written consent prior to the commencement of the study.

Consent for publication

Signed consent provided by the patient.

\section{Competing interests}

The authors declare that they have no competing interests.

\section{Author details}

${ }^{1}$ Department of Medical Rehabilitation (Physical Therapy), College of Applied Medical Sciences, King Khalid University, Abha 61421, Saudi Arabia.

2Department of Basic Medical Sciences, College of applied medical sciences, King Khalid University, Abha, Saudi Arabia.

Received: 6 May 2019 Accepted: 20 September 2019

Published online: 15 October 2019

References

1. Hogg-Johnson S, Van Der Velde G, Carroll LJ, Holm LW, Cassidy JD, Guzman J, Côté P, Haldeman S, Ammendolia C, Carragee E. The burden and determinants of neck pain in the general population. Eur Spine J. 2008; 17(1):39-51.

2. Radhakrishnan K, Litchy WJ, O'Fallon WM, Kurland LT. Epidemiology of cervical radiculopathy: a population-based study from Rochester, Minnesota, 1976 through 1990. Brain. 1994;117(2):325-35.

3. Binder Al. Cervical spondylosis and neck pain. Bmj. 2007:334(7592):527-31.

4. Strimpakos N, Sakellari V, Gioftsos G, Kapreli E, Oldham J. Cervical joint position sense: an intra-and inter-examiner reliability study. Gait Posture. 2006;23(1):22-31.

5. van der Wal J. The architecture of the connective tissue in the musculoskeletal system - an often overlooked functional parameter as to proprioception in the locomotor apparatus. Int J Ther Massage Bodywork. 2009:2(4):9

6. Lee H-Y, Wang J-D, Yao G, Wang S-F. Association between cervicocephalic kinesthetic sensibility and frequency of subclinical neck pain. Man Ther. 2008;13(5):419-25

7. Fenlin JM Jr. Pathology of degenerative disease of the cervical spine. Orthop Clin North Am. 1971;2(2):371-87.

8. Valergakis FE. Cervical spondylosis: most common cause of position and vibratory sense loss. Geriatrics. 1976;31(7):51-6.

9. Revel M, Andre-Deshays C, Minquet M. Cervicocephalic kinesthetic sensibility in patients with cervical pain. Arch Phys Med Rehabil. 1991;72(5): 288-91.

10. Heikkilä H, Johansson M, Wenngren B-I. Effects of acupuncture, cervical manipulation and NSAID therapy on dizziness and impaired head repositioning of suspected cervical origin: a pilot study. Man Ther. 2000; 5(3):151-7.

11. Chiu TT, Lam T-H, Hedley AJ. A randomized controlled trial on the efficacy of exercise for patients with chronic neck pain. Spine. 2005;30(1):E1-7.

12. Capuano-Pucci D, Rheault W, Aukai J, Bracke M, Day R, Pastrick M. Intratester and intertester reliability of the cervical range of motion device. Arch Phys Med Rehabil. 1991;72(5):338-40.

13. Alahmari K, Reddy RS, Silvian P, Ahmad I, Nagaraj V, Mahtab M. Intra-and inter-rater reliability of neutral head position and target head position tests in patients with and without neck pain. Braz J Phys Ther. 2017;21(4):259-67.

14. Reips UD, Funke F. Interval-level measurement with visual analogue scales in internet-based research: VAS generator. Behav Res Methods. 2008;40(3): 699-704.

15. de Vet HC, Terwee CB, Ostelo RW, Beckerman H, Knol DL, Bouter LM. Minimal changes in health status questionnaires: distinction between minimally detectable change and minimally important change. Health Qual Life Outcomes. 2006;4(1):54. 
16. Fitzgerald SM, Rumrill PD Jr, Schenker JD. Correlational designs in rehabilitation research. J Vocational Rehabil. 2004;20(2):143-50.

17. Treleaven J. Sensorimotor disturbances in neck disorders affecting postural stability, head and eye movement control. Man Ther. 2008;13(1):2-11.

18. Rix GD, Bagust J. Cervicocephalic kinesthetic sensibility in patients with chronic, nontraumatic cervical spine pain. Arch Phys Med Rehabil. 2001; 82(7):911-9.

19. Roren A, Mayoux-Benhamou M-A, Fayad F, Poiraudeau S, Lantz D, Revel M. Comparison of visual and ultrasound based techniques to measure head repositioning in healthy and neck-pain subjects. Man Ther. 2009;14(3):270-7.

20. Wibault J, Vaillant J, Vuillerme N, Dedering A, Peolsson A. Using the cervical range of motion (CROM) device to assess head repositioning accuracy in individuals with cervical radiculopathy in comparison to neck-healthy individuals. Man Ther. 2013;18(5):403-9.

21. Gandevia S, McCloskey D, Burke D. Kinaesthetic signals and muscle contraction. Trends Neurosci. 1992;15(2):62-5.

22. Ribot-Ciscar E, Roll J-P. Ago-antagonist muscle spindle inputs contribute together to joint movement coding in man. Brain Res. 1998;791(1-2): 167-76.

23. Prushansky T, Gepstein R, Gordon C, Dvir Z. Cervical muscles weakness in chronic whiplash patients. Clin Biomech (Bristol, Avon). 2005;20(8):794-8.

24. Vernon HT, Aker P, Aramenko M, Battershill D, Alepin A, Penner T. Evaluation of neck muscle strength with a modified sphygmomanometer dynamometer: reliability and validity. J Manip Physiol Ther. 1992;15(6):343-9.

25. Ylinen J, Salo P, Nykanen M, Kautiainen H, Hakkinen A. Decreased isometric neck strength in women with chronic neck pain and the repeatability of neck strength measurements. Arch Phys Med Rehabil. 2004;85(8):1303-8.

26. Barton PM, Hayes KC. Neck flexor muscle strength, efficiency, and relaxation times in normal subjects and subjects with unilateral neck pain and headache. Arch Phys Med Rehabil. 1996;77(7):680-7.

27. Jordan A, Mehlsen J, Ostergaard K. A comparison of physical characteristics between patients seeking treatment for neck pain and age-matched healthy people. J Manip Physiol Ther. 1997;20(7):468-75.

28. Gogia PP, Sabbahi MA. Electromyographic analysis of neck muscle fatigue in patients with osteoarthritis of the cervical spine. Spine (Phila Pa 1976). 1994; 19(5):502-6.

29. Hill JM. Increase in the discharge of muscle spindles during diaphragm fatigue. Brain Res. 2001;918(1-2):166-70.

30. Pedersen J, Ljubisavljevic M, Bergenheim M, Johansson $H$. Alterations in information transmission in ensembles of primary muscle spindle afferents after muscle fatigue in heteronymous muscle. Neuroscience. 1998;84(3):953-9.

31. Capra NF, Ro JY. Experimental muscle pain produces central modulation of proprioceptive signals arising from jaw muscle spindles. Pain. 2000;86(1-2): $151-62$.

32. Johansson H, Djupsjobacka M, Sjolander P. Influences on the gammamuscle spindle system from muscle afferents stimulated by $\mathrm{KCl}$ and lactic acid. Neurosci Res. 1993;16(1):49-57.

33. Reddy RS, Alahmari KA, Silvian PS. Test-retest reliability of assessing cervical proprioception using cervical range of motion device. Saudi J Sports Med. 2016;16(2):118

34. Heikkilä H, Aström P. Cervicocephalic kinesthetic sensibility in patients with whiplash injury. Scand J Rehabil Med. 1996;28(3):133-8.

35. Swait G, Rushton AB, Miall RC, Newell D. Evaluation of cervical proprioceptive function: optimizing protocols and comparison between tests in normal subjects. Spine (Phila Pa 1976). 2007;32(24):E692-701.

\section{Publisher's Note}

Springer Nature remains neutral with regard to jurisdictional claims in published maps and institutional affiliations.

Ready to submit your research? Choose BMC and benefit from:

- fast, convenient online submission

- thorough peer review by experienced researchers in your field

- rapid publication on acceptance

- support for research data, including large and complex data types

- gold Open Access which fosters wider collaboration and increased citations

- maximum visibility for your research: over $100 \mathrm{M}$ website views per year

At $\mathrm{BMC}$, research is always in progress.

Learn more biomedcentral.com/submissions 